\title{
EXOFTALMO UNILATERAL POR METÁSTASE ORBITÁRIA DE CARCINOMA DE PRÓSTATA
}

\author{
José Carlos Corrêa Barbosa*
}

\begin{abstract}
O exoftalmo ou proptose unilateral pode ser determinado por fatôres anátomofísiológicos e patológicos. Entre os primeiros podem ser considerados o tamanho do ôlho, a profundidade da órbita, a quantidade de gordura intraorbitária, o tono dos músculos extrínsecos, a drenagem venosa da órbita e, segundo Birch-Hirschfeld ${ }^{5}$, a compressão direta da veia jugular $e$ a posição da cabeça. A proptose foi obtida por estimulação do tronco simpático cervical em animais de experimentação (Claude Bernard ${ }^{4}$, Müller ${ }^{11}$, Mac Callum \& Cornell ${ }^{10}$ e Landström ${ }^{9}$ ). Segundo Barraquer e Cañadell ${ }^{2}$ existiria, no sôro de pacientes mixedematosos, um fator que, injetado no Carassius auratus, variedade japônica, provocaria, ao fim de 4 a 8 aplicações, exoftalmo unilateral. Experimentos de Wagner ${ }^{14}$ e Turner ${ }^{13}$, mediante estimulação do simpático cervical em cabeças isoladas não provocaram exoftalmo.
\end{abstract}

No que concerne à patologia, vários autores têm abordado o tema de forma genérica, ou relatando entidades mórbidas intraorbitárias ou, ainda, referindo causas extraordinárias.

Numerosas são, portanto, as causa da proptose unilateral, considerando-se como anormalidade, diferença de protusão ocular acima de dois $\mathrm{mm}$. Corrêa Barbosa e Menezes, em 1964, apresentaram ao $1 .^{\circ}$ Congresso Brasileiro de Neurologia (Ribeirão Prêto, São Paulo), alguns casos raros estudados no Instituto de Neurologia da Universidade do Brasil (Prof. Deolindo Couto), de proptose unilateral causados por cisto sebáceo intraorbitário, carcinoma espinhoso de abóbada palatina, doença de Recklinghausen, oligodendroglioma frontal, cisto epidermóide intraorbitário, neurinoma do acústîco, fibrodisplasia orbitária, miosite extraocular, perineurite e astrocitoma do nervo óptico; dos restantes 32 casos apresentados naquela ocasião, nenhum se referia a metástase orbitária de carcinoma da glândula prostática. Na literatura que pudemos compulsar, apenas Bard \& Schulze ${ }^{2}$, Bonnet e Paufique $^{6}$ e Harper ${ }^{8}$ relatam a ocorrência de exoftalmo unilateral provocado por metástase, na órbita, de câncer da próstata. A raridade desta ocorrência justifica o relato de um caso pessoal.

* Professor Assistente de Neurologia no Departamento de Neuro-Psiquiatria (Serviço do Prof. Milton Figueiredo) da Faculdade de Medicina da Universidade Federal de Juiz de Fóra (Minas Gerais). 


\section{OB SER V A C A O}

M.J.S., com 68 anos de idade, sexo masculino, preto, internado na Santa Casa de Misericórdia de Juiz de Fora, em 16-12-1969 (Reg. 234501), queixando-se de epifora e protusão ocular direita, datando de 9 meses. A protusão começou insidiosamente, agravando-se progressivamente, acompanhada por crescimento indolor da parede óssea adjacente. Pouco tempo depois manifestaram-se embaçamento da vísão e limitação dos movimentos oculares no ôlho atingido. Queixava-se também de retenção urinária na época do internamento. Recentemente, começou a sentir dores na parte superior da coxa esquerda que dificultava a deambulação. Nada digno de nota nos antecedentes pessoais e familiares. Ao exame físico, o fato maicante era exoftalmo pronunciado à direita com aumento de volume da porção órbito-zigomática homolateral (Fig. 1). Comparado com o esquerdo, o globo ocular protundia $10 \mathrm{~mm}$. Os movimentos oculares eram limitados. As pupilas reagiam dèbilmente à luz e à acomodação. Havia perda da convergência ocular, bem como precária visão de côres. A agudeza visual à direita permitia ao paciente distinguir vultos. O fundo de ôlh:) revelava aumento do reflexo luminoso central e diminuição do calibre arteriolar. A glândula tireóide não estava aumentada, não havia ruídos audiveis no ôlho, cabeça ou pescoço. O exame cardiológico foi satisfatório. O exame prostático revelou hipertrofia de grau médio, sendo a glândula de consistência pétrea, principalmente no lóbo lateral direito. Exames complementares - No sangue, 4.080.000 hemácias por $\mathrm{mm}^{3}$. Exames de urina e fezes foram negativos. Testes de Kahn, Kline e VDRL para lues, negativos. Normais as provas de função hepática. Dosagem de fosfatase ácida total no sangue (Bodansky) 2,1 unidades; fosfatase ácida prostática foi dosada no sangue a 1,6 unidades Bodansky. O exame radiológico do tórax mostrou discretos sinais de estase circulatória bilateral, velamento do seio costofrênico direito e pequeno aumento do ventriculo esquerdo. Os exames radiológicos simples do fêmur esquerdo, pelve, crânio, órbitas e contrastados do crânio mostravam alterações sugestivas de metástases ósseas difusas. Exame do liquido céfalorraqueano mediante punção lombar mostrou, de anormal, 12 células $/ \mathrm{mm}^{3}$ (15\% de polinucleares neutrófilos); tanto as proteinas quanto as outras dosagens bioquimicas foram normais; a pesquisa de células neoplásicas foi negativa. A biópsia do tumor ósseo, revelou tratar-se de metástase (Figs. 2 e 3 ).
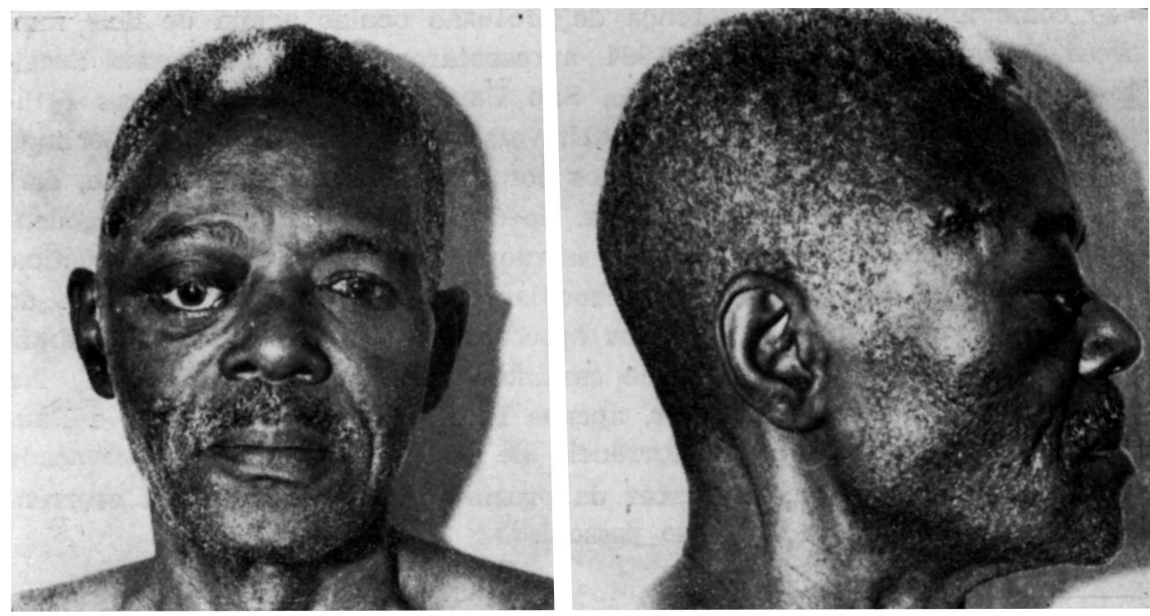

Frig. 1 - Caso M.J.S. - Fotografias mostrando exoftalmo unilateral, aumento do volume da porscão órbito-zigomática e cicatriz de biópsia. 

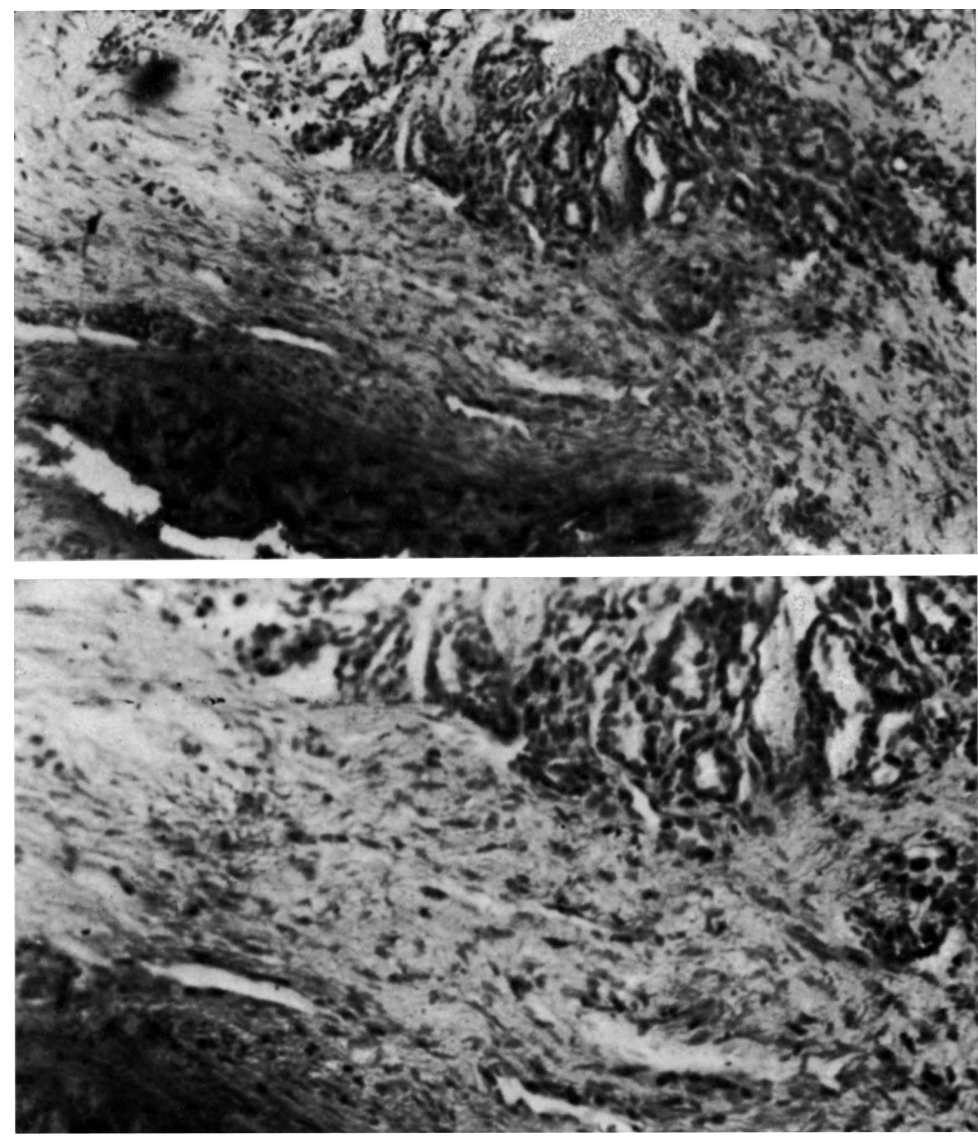

Fig. 2 - Caso M.J.S. Na parte superior, microfotografia de fragmento de tumor órbito-zigomático, mostrando porção de tecido ósseo e massa tumoral envolvida por estroma conjuntivo (Wilde $M$ 20, $100 \mathrm{x})$; na parte inferior, mesmo aspecto da figura anterior em maior aumento (Wilde $M$ 20, $200 x$ ).

\section{COMENTARIOS}

No caso relatado, trata-se de exoftalmo ou proptose unilateral direita, com evolução de 9 meses, em paciente negro, na $6 .^{7}$ década de vida, o qual apresenta tumor ósseo adjacente, causador da protusão, além da queixa de retenção urinária. No decorrer da investigação clínica, laboratorial e radiológica, foram excluídas as causas locais e gerais que poderiam ocasionar a manifestação em aprêço, chegando-se, ao final, à verificação de que se tratava de metástase orbitária de carcinoma da próstata, existindo outras metástases ósseas difusas. 

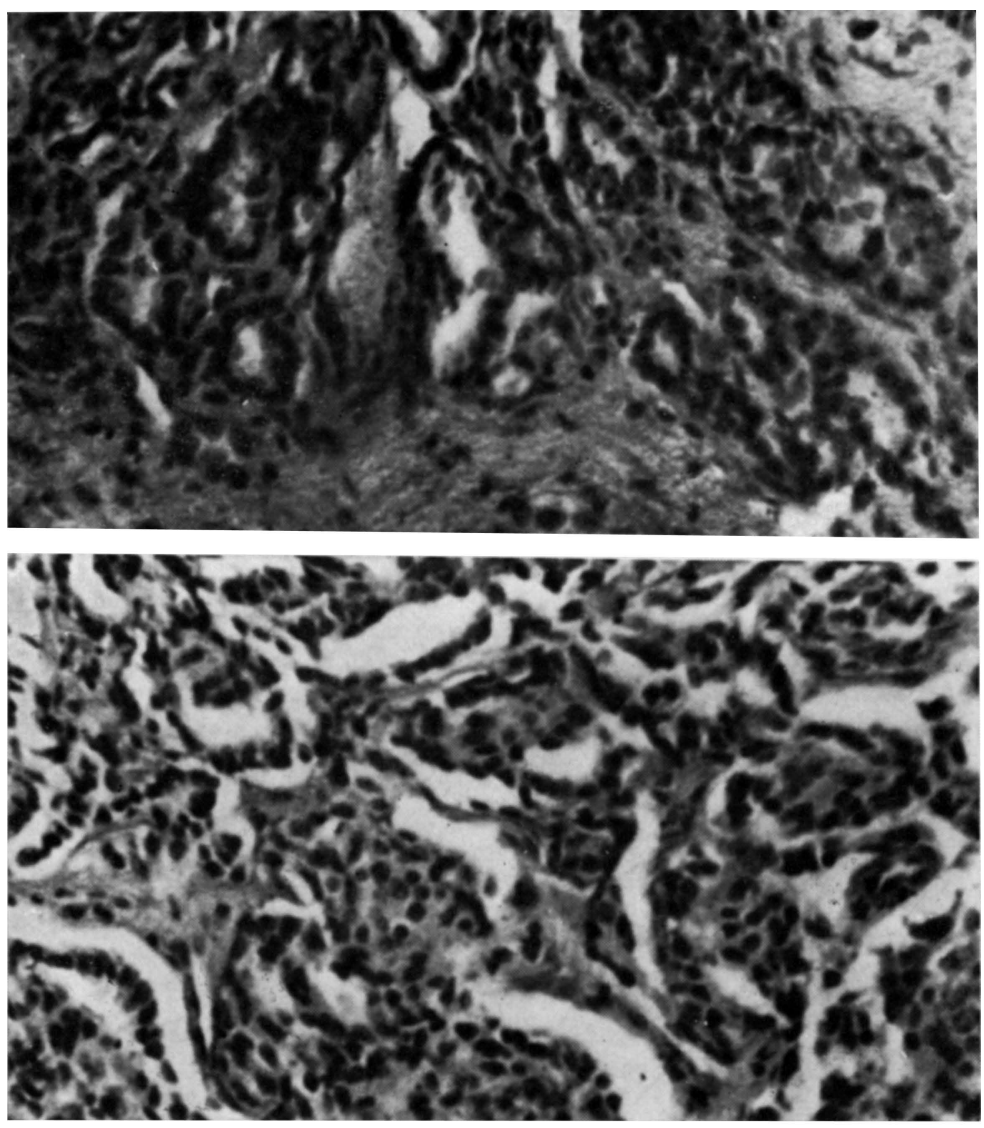

Fig. 3 - Caso M.J.S. Na parte superior, microfolografia de fragmento de tumor órbito-zigomático com estrutura tumoral, mostrando glândulas semelhantes às prostáticas (Wilde $M$ 20, $400 \mathrm{x})$; na parte inferior, microfotografia de fragmento ae tumor órbito-zigomático, mostrando estruturas típicas de glandulas prostáticas. (Wilde $M 20,400 x$ ).

Embora não tenha sido possivel extrair cirùrgicamente a glândula por oposição dos familiares, afirmamos que se trata de carcinoma, baseados nos seguintes elementos: $a$ ) consistência pétrea em um dos lóbos da próstata, o que é quase patognomônico do carcinoma; b) metástases ósseas difusas, comprometendo fêmur esquerdo, pelve, calota craniana e órbita direita; c) aumento da fosfatase ácida total no sangue, sinal de carcinoma de próstata metastatizado (Barcells-Gorina ${ }^{1}$ ); $d$ ) aumento da fosfatase ácida prostática no sangue, com o mesmo valor do item anterior; e) biópsia do tumor ósseo orbitário, confirmando tratar-se de metástase de origem prostática. 
Se não fossem conclusivos os dados assinalados, bastariam os bons resultados obtidos com a medicação específica (Honvan) que, além da prova terapêutica, ocasionou razoável melhora dos distúrbios urinários e da dôr na parte superior da coxa esquerda. Infelizmente, em 6 meses do evolver da moléstia, ocorreu o êxito letal.

\section{R ES U M O}

E relatado um caso de exoftalmo ou proptose unilateral direita, causado por metástase orbitária de carcinoma da próstata em paciente negro, na 6. década de vida, com evolução de 9 meses. O exame neuro-ocular revelou acentuada diminuição da agudeza visual, perturbação para visão de côres, perda da convergência, diminuição dos reflexos à luz e acomodação e restrição dos movimentos oculares. O paciente apresentava discreta disbasia esquerda por metástase no fêmur. Exames laboratoriais, radiológicos e a biópsia confirmaram a etiologia carcinomatosa da manifestação ocular.

\section{S U M M A R Y}

\section{Unilateral exophthalmos secondary to orbital metustatic carcinoma of the prostate: a case report.}

A case of right unilateral exophthalmos secondary to metastatic carcinoma of the prostate, in a 68 years old negro patient in which the ocular manifestation lasted 9 months is reported The extrinsic movements of the eye were limited. Pupils reacted slightly to light and accommodation. There was no ocular convergence. The vision of the right eye was blurred and there was mild color vision. The prostate was found to be petrous by touch specially in the right portion. The laboratory findings pointed to a prostatic carcinoma. Bone X-rays were strongly suggestive of metastatic tumour. The histological examination of the orbital tumour showed prostatic tumour cells.

1. BARCELls-gorina, A. - La Clinica y el Laboratorio. Manuel Morin e Cia., Barcelona, 1959-1961.

2. BARD, L. A. \& SCHULZE, R. R. - Unilateral proptosis as the presenting sign of metastatic carcinoma of the prostate. Amer. T. Ophtal. 58:107, 1964.

3. BARRAQUER, J. \& CANADELL, J. M. - El factor exoftaimogeno del suero. Rev. Esp. Oto-neuro-oftalmol. y Neurocir. 15:437, 1956.

4. BERNARD, C. - Cit. por FULTON ?.

5. BIRCH-HIRSCHFELD, A. - Cit. por WALSH ${ }^{15}$.

6. BONNET, P. \& PAUFIQUE, L. - L'exophtalmie unilatérale par tumeur de l'orbite metastase d'un cancer latent de la prostate. Bull. Soc. d'Ophtalm. (Paris) $51: 63,1939$.

7. FULTON, J. - Fisiologia do Sistema Nervoso. Versão brasileira da 2.* edição americana. Editôra Científica, Rio de Janeiro, 1943. 
8. HARPER, J. M. - Unilateral exophthalmos secondary to metastatic carcinoma of the prostate; case report and review of the litterature. 'l. Urol. 89:75, 1963.

9. LANDSTROM - Cit, por CODE e ESSEX. In FULTON ?.

10. MAC CALLUM \& CORNELL - Cit. por CODE e ESSEX. In FULTON ?

11. MULLER, H. - Cit. por FULTON ?

12. OFFret, G. - Les Tumeurs Primitives de l'Orbite. Masson et Cie. Paris, 1951.

13. TURNER, W. - Cit. por FULTON ?.

14. WAGNER - Cit. por FULTON ?.

15. WALSH, C. B. - Clinical Neuro-Ophtalmology. The Williams and Wilkins Co., Baltimore, 1947.

Santa Casa de Misericórdia - Avenida Rio Branco $\$ \$ 5 s$ - $\$ 6100$ Juiz de Fóra, $M G$ - Brasil. 